$2.3 \%$ would not request neuraxial analgesia in a next pregnancy.

Conclusions In our sample, there was a high adherence to neuraxial analgesia (92.2\%), with an even distribution between epidural and combined spinal-epidural techniques. Even with minor side effects, mainly pruritus, most women were satisfied and $97.7 \%$ would request neuraxial analgesia again.

\section{TIME TO EXPAND THE DIAGNOSTIC AND INTERVENTIONAL USES OF ULTRASOUND IN OBSTETRIC ANAESTHESIA - INTRODUCING A HOLISTIC COURSE AT A LONDON TERTIARY OBSTETRIC HOSPITAL}

Y Mandour*, M Khaku, H Caulfield, I Dick. University College London Hospitals NHS Foundation Trust, London, UK

\subsection{6/rapm-2021-ESRA.106}

Background and Aims Ultrasound use is expanding our anaesthetic practice in obstetrics for both diagnostic and interventional purposes. These include scans for central neuraxial blockade, truncal blockade and finally focussed point-of-care ultrasound scans (POCUS). We aimed to design and deliver a practical course to enhance knowledge and skills in these areas.

\section{Abstract 106 Table 1 Course contents}

\begin{tabular}{|c|c|}
\hline Lectures & Workshops \\
\hline \multicolumn{2}{|c|}{ US guided Central Neuraxial blockade } \\
\hline \multicolumn{2}{|c|}{ Truncal blocks - US guided TAP \& QL blocks } \\
\hline \multicolumn{2}{|c|}{ POCUS - Cardiac } \\
\hline \multicolumn{2}{|c|}{ POCUS - Airway \& lungs } \\
\hline \multicolumn{2}{|c|}{$\begin{array}{l}\text { Focussed Assessment with sonography for } \\
\text { trauma (FAST) scanning }\end{array}$} \\
\hline $\begin{array}{l}\text { Anticoagulants in } \\
\text { regional anaesthesia }\end{array}$ & \\
\hline $\begin{array}{l}\text { Updates/ Complications } \\
\text { of regional anaesthesia }\end{array}$ & \\
\hline
\end{tabular}

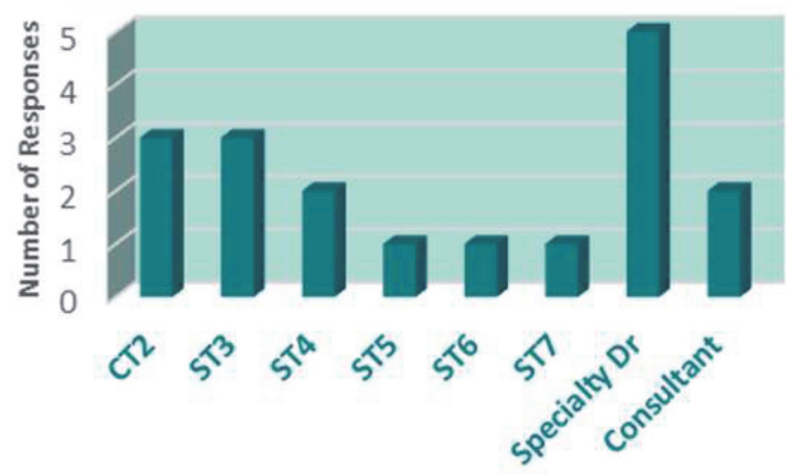

Training Grade

Abstract 106 Figure 1 Training grades of course candidates

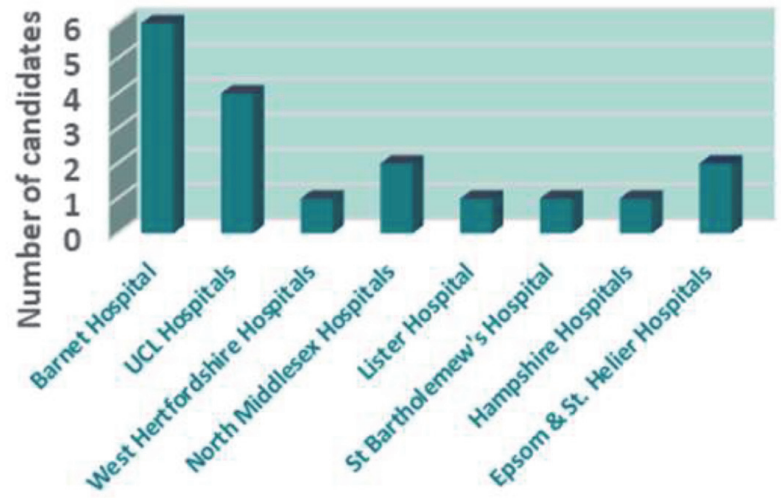

Abstract 106 Figure 2 Hospitals of course candidates

Methods Our course consisted of a series of lectures and corresponding small-group workshops which covered the topics in table 1.

The course included candidates of all training grades in the UK (figure 1).

Candidates represented eight large NHS Trusts in South East England (figure 2).

Results We achieved a $100 \%$ response rate to our post-course evaluation survey (18/18). All attendees gave global positive feedback about our multi-dimensional educational tool for the use of this technology in obstetric anaesthesia. The majority of candidates expressed more interest in workshops and hands-on training.

Conclusions Ultrasound technology is enriching obstetric anaesthesia with diagnostic and interventional techniques which are invaluable for parturients with multiple comorbidities or trauma victims. National anaesthetic training programme in the UK training modules for obstetric anaesthesia should strive to recognise the use of ultrasound as an integral part of this complex subspecialty.

\section{COMPARING ULTRASOUND TO BODY MASS INDEX FOR MEASUREMENT OF DURAL DEPTH}

T Al-Ani*. Glasgow Royal Infirmary, Glasgow, UK

\subsection{6/rapm-2021-ESRA.107}

Background and Aims Measuring the distance from the skin to posterior dura (SPD) before lumbar epidural placement may prevent accidental dural puncture. ${ }^{1}$ This study compares the accuracy of measurement of SPD using ultrasound versus body mass index (BMI) in obstetric patients.

Methods An anonymous retrospective data of pre-procedural ultrasound and intraprocedural Tuohy needle measurements of SPD were collected from anaesthetic charts of thirty parturient with varying gestational stages, maternal age and ethnicity, all had received lumbar epidurals for labour analgesia using 18G Tuohy needle and loss of resistance to saline. Then, using the documented patient's BMI the SPD was calculated using the general regression equation $(\mathrm{Y}=2.52+0.11 \mathrm{BMI}){ }^{2}$ The accuracy of measurement of SPD for the two groups: Ultrasound SPD versus BMI SPD compared to the Touhy needle SPD was analysed using Wilcoxon signed-rank test. Ethics approval is not required as per NHS Greater Glasgow and Clyde policy. 
Results Ultrasound measurement of SPD was equal to Touhy needle in 23/30 (76.7\%), while overestimated in $1 / 30(3.3 \%)$ by $0.2 \mathrm{~cm}$ and underestimated in $6 / 30(20 \%)$ by a mean of $0.5 \mathrm{~cm}$. BMI measurement of SPD was equal to Touhy needle in $0 / 30(0 \%)$, while overestimated in $25 / 30(83.3 \%)$ by a mean of $1.14 \mathrm{~cm}$ and underestimated in $5 / 30(16.7 \%)$ by a mean of $0.29 \mathrm{~cm}$. Ultrasound was more accurate than BMI in the measurement of SPD based on Wilcoxon signed-rank test (non-parametric) with a p-value $<0.00001$.

Conclusions Compared to BMI, ultrasound offers more accurate measurement of SPD.

\section{POST-CESAREAN SECTION ANALGESIA WITH QUADRATUS LUMBORUM BLOCK 5 IN A PUERPERAL WOMAN: A CASE REPORT}

L Vieira, B Alves* , CR Almeida. Centro Hospitalar Tondela Viseu, Viseu, Portugal

10.1136/rapm-2021-ESRA.108

Background and Aims A 42-year-old pregnant woman refused neuroaxial anaesthesia for a scheduled cesarean section (c-section), therefore a balanced general anaesthesia was performed. The c-section was uneventful. Before extubation, in a supine position, an ultrasound guided lumbar bilateral quadratus lumborum block (QLB) 5 was performed with a single shot dose of $20 \mathrm{ml}$, per side, of ropivacaine $0,5 \%$. During the first 24 hours post-operative, the patient remained comfortable, with paracetamol $1 \mathrm{~g}$ every 8 hours, intravenously, without other analgesic medication.

Methods Different variations of QLB have been performed for analgesia after c-section, but Transmuscular QLB (T-QLB) is frequently chosen, due to long lasting duration and to better visceral analgesia, but the patient must be positioned in both lateral position alternately.

Results Recently Almeida et al, ${ }^{2}$ described the QLB5 and the LAlat Block, the latter not for abdominal pain, using the same sonoanatomy of the T-QLB, but maintaining the supine position. The anesthetic is injected from anterior/lateral to posterior/medial direction between the psoas major muscle (PMM)

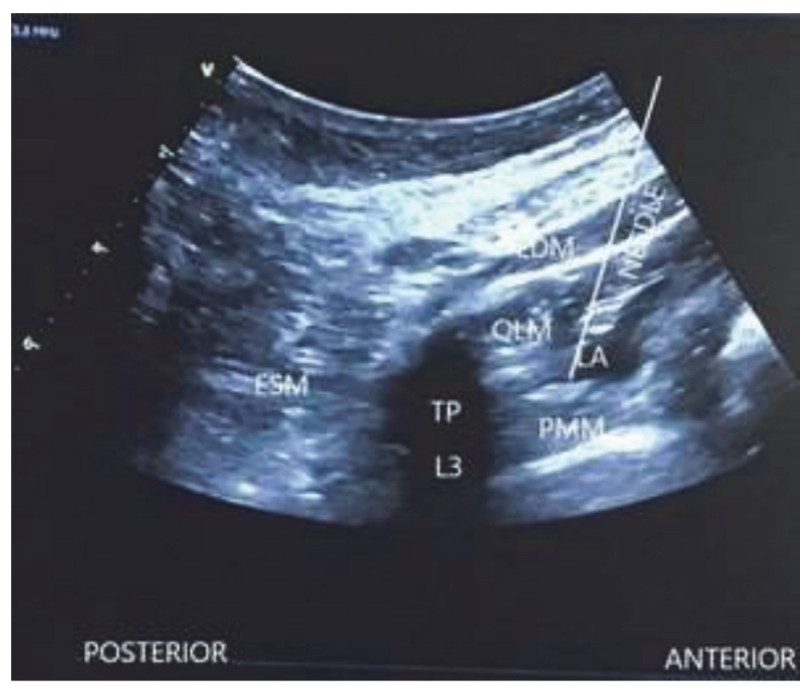

Abstract 108 Figure 1 Ultrasound image showing performance of a modified anterior QLB, a novel QLB 5. ESM, Erector spinae muscle; LA, Local anaesthetic. and the quadratus lumborum muscle (QLM) (figure 1). The insertion point at QLB5 is anterior to the probe. This approach (QLB5) provides similar dispersion as the T-QLB; the gravid uterus or other abdominal structure are easily avoided as with the T-QLB; this happens because QLM functions as a safe path for the needle.

Conclusions The QLB5 is safe and allows prolonged abdominal (somatic and visceral) analgesia for post-c-section.

\section{AN AUDIT OF RESPONSE TIMES TO EPIDURAL REQUESTS ON A BUSY UK LABOUR WARD}

T Moody*, A Qureshi, M Nejdlova. University Hospital Birmingham, Birmingham, UK

\subsection{6/rapm-2021-ESRA.109}

Background and Aims Epidural analgesia is the gold standard for labour analgesia. Recently the availability and timing of an epidural has been topical in the UK news ${ }^{3,4,5}$. The time from an anaesthetist being informed of epidural request to attendance should be less than 30 minutes; or 60 in exceptional circumstances. This single centre audit aims to assess anaesthetic attendance times according to the standards set by the OAA and AAGBI ${ }^{1,2}$.

Methods We looked at all epidural requests over 3 months at a busy UK maternity unit. With each epidural, the time of request, the time of anaesthetist being informed and the time of attendance of anaesthetist were noted. Reasons for delays, including delays between the request and informing the anaesthetist were recorded.

Results 31 from 50 epidural requests had the anaesthetist attend within 30 minutes of being informed. The anaesthetist attended 37 times within 60 minutes of being informed.

The most common reasons for delay were unavailability of the anaesthetist, the anaesthetist not being informed, CTG concerns and awaiting blood results.

Conclusions Out of hours, one resident anaesthetist was on call with a non-resident consultant. If a case was on-going in theatre, this potentially delayed discussion for epidural. It highlights the need for additional resident labour ward anaesthetists at busy units in line with GPAS guidelines ${ }^{1}$. In our unit we rolled out an educational program aimed at educating

\section{Abstract 109 Table 1}

\begin{tabular}{|c|c|}
\hline 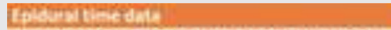 & 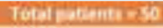 \\
\hline $\begin{array}{l}\text { Anaesthetint attending within } 30 \text { minutes of } \\
\text { being informed }\end{array}$ & $31 / 50$ \\
\hline $\begin{array}{l}\text { Ansesthetist attending within } 60 \text { minutes of } \\
\text { being informed }\end{array}$ & $37 / 50$ \\
\hline $\begin{array}{l}\text { Ansesthetist attending withis } 30 \text { minutes of } \\
\text { initial respest }\end{array}$ & $27 / 50$ \\
\hline Reason for delay documented in patient notes & 25,50 \\
\hline
\end{tabular}

Abstract 109 Table 2

\begin{tabular}{|c|c|}
\hline 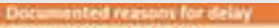 & 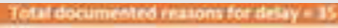 \\
\hline Ansesthetist unwralibble & 10 \\
\hline Ansesthetist not informed & 7 \\
\hline CTG conteens & 5 \\
\hline Blood revolts unavailable & s \\
\hline Lack of trained mildwile & 3 \\
\hline Delivery is likely imminent & 2 \\
\hline Datient awaiths obstetrix review & 1 \\
\hline Equipment iswes & 1 \\
\hline Awaining viterotonirs to start & 1 \\
\hline
\end{tabular}

